\title{
EKSPERIMEN LABORATORIUM ALIRAN TERTUTUP DAN INISIASI UJI BENDUNG BERPORI UNTUK KAWASAN PERTANIAN
}

\author{
S. Imam Wahyudi ${ }^{*}$, \\ Henny Pratiwi Adi' ${ }^{2}$, \\ A. Khamid ${ }^{3}$ \\ Program Studi Teknik Sipil Universitas Islam Sultan Agung, Jl. Raya Kaligawe Km. 4 Semarang ${ }^{1,2,3}$ \\ Penulis korespondensi email: wahyudi@unissula.ac.id ${ }^{1}$
}

\begin{abstract}
The problem of water utilization for agricultural areas, the handling of problems in tidal flood areas requires analysis using numerical models and validation using physical model tests. This study aims to add a closed flow test component and an initial flow test with a porous weir sample. The method used in this research includes inventorying the existing laboratory conditions, making existing plans, planning flow circulation, placing the necessary measuring instruments, allocating water building model tests, and planning detailed hydraulics testing laboratories. This research begins with the porous weir test. This research results in laboratory planning for physical testing model, experimentation research, flow improvement. Then this research also produced preliminary analysis of laboratory experiments for porous weirs with three types of gabion shapes. The results of this study can be implemented in agricultural areas that have relatively small rivers or streams.
\end{abstract}

Keywords: closed flow, weir, porous, agricultural area

\begin{abstract}
ABSTRAK
Permasalahan pemanfaatan air untuk kawasan pertanian, penanganan permasalahan kawasan banjir rob memerlukan analisis dengan menggunakan model numerik dan validasi dengan uji model Fisik. Penelitian ini bertujuan untuk menambahkan komponen uji aliran tertutup dan uji awal aliran dengan sampelk bendung berpori. Metode yang digunakan dalam penelitian ini meliputi inventori kondisi eksisting laboratorium, pembuatan denah eksisting, perencanaan sirkulasi aliran, penempatan alat ukur yang diperlukan, alokasi uji model bangunan air, detail perencanaan laboratorium uji hidrolika. Untuk penelitian ini diawali dengan uji bendung berpori. Penelitian ini menghasilkan perencanaan laboratorium untuk uji hidrolika, penelitian eksperimen dan perbaikan alur aliran laboratorium. Kemudian penelitian ini juga menghasilkan analisis uji awal eksperimen laboratorium untuk bendung berpori dengan tiga tipe bentuk bronjong. Hasil penelitian ini dapat diimplementasikan di kawasan pertanian yang memiliki sungai atau aliran yang relatif kecil.

Kata kunci: aliran tertutup, bendung, berpori, kawasan pertanian
\end{abstract}


Jurnal Planologi Vol. 18 No. 1, April 2021 Available: http://jurnal.unissula.ac.id/index.php/psa

\section{PENDAHULUAN}

Dalam pengelolaan sumber daya air, kita harus mempunyai sarana dan prasarana penunjang yang memadai, salah satunya adalah irigasi untuk memajukan kawasan pertanian. Dengan adanya irigasi yang baik pengolahan lahan pertanian dapat dilakukan secara maksimal. Jika hanya mengandalkan pengairan dari curah hujan, frekuensi panen hanya sekali dalam setahun. Dengan bantuan infrastruktur irigasi, diantaranya bendung, kawasan pertanian tersebut bisa dua kali atau tiga kali panen setahun. (Tsuchiya, Hara, \& Thaitakoo, 2015). Untuk membangun irigasi yang baik perlu dipilih lokasi yang ideal, aliran sungai yang cukup besar serta pengaturan dan pembagian air yang baik. Salah satu pengaturan air tersebut adalah dengan bendung berpori.

Untuk memenuhi hal ini maka perlu dibangun bedung pada aliran sungai, dimana fungsi dari bendung ini adalah untuk menaikkan tinggi muka air dan menstabilkan debit air sehingga aliran sungai ini masih bisa dimanfaatkan untuk mengairi kawasan pertanian sepanjang tahun, walaupun pada musim kemarau. (Niken RTH, Imam Wahyudi, \& Poedjiastoeti, 2019)

Bendung atau pelimpah adalah suatu bangunan yang dibuat dari pasangan batu kali, bronjong atau beton, yang terletak melintang pada sebuah sungai dan dapat digunakan pula untuk kepentingan lain selain irigasi, seperti untuk keperluan air minum, pembangkit listrik atau untuk pengendali banjir dan rob. (Boogaard, F., Heikoop, R., Boer, E., \& Palsma, 2017) dan (Wahyudi, Adi, \& Lekkerkerk, 2019). Menurut jenisnya bendung dibagi dua, yaitu bendung tetap dan bendung sementara, bendung tetap adalah bangunan yang sebagian besar konstruksi terdiri dari pintu yang dapat digerakkan untuk mengatur ketinggian muka air sungai sedangkan bendung tidak tetap adalah bangunan yang dipergunakan untuk meninggikan muka air di sungai, sampai pada ketinggian yang diperlukan agar air dapat dialirkan ke saluran irigasi dan petak tersier. Tujuan dari tahapan penelitian ini yaitu merencanakan dan mewujudkan sirkuit aliran tertutup dan mewujudkan implementasi awal uji sampel bendung Porous.

\section{METODE PENELITIAN}

Berikut tahapan penelitian yang dilakukan yaitu studi pustaka permodelan fisik laboratorium, kemudian mengindentifikasi beberapa permasalahan untuk realisasi laboratorium Uji Hidrolika. Setelah data terkumpul dibuat gambar kondisi eksisting denah laboratorium Hidrolika FT Unissula. Kemudian setelah merealisasikan modifikasi aliran 
tertutup dengan kelengkapan instrumentasi (Hiwasaki, Luna, Syamsidik, \& Shaw, 2014). Di laboratorium, dilakukan inisiasi uji aliran dengan uji awal bendung berpori. Ada 3 tipe bendung berpori yang diuji. Untuk tahap awal tiap tipe diuji dengan beberapa beda tinggi air dan debit yang bervariasi sesuai kondisi di kawasan pertanian.

\section{HASIL DAN PEMBAHASAN}

Hasil dalam penelitian ini dibagi menjadi dua yaitu proses penyusunan aliran tertutup dan instrumentasi laboratorium, kemudian inisiasi uji eksperimen untuk bendung berpori. Uji bendung berpori ini direncanakan untuk aplikasi di kawasan pertanian sebagai teknologi tepat guna.

\subsection{Penyusunan Aliran Tertutup dan instrumentasi eksperimen labororium}

Komponen aliran tertutup untuk eksperimen penelitian laboratorium di antaranya terdiri dari pompa, tampungan air, pintu pengatur aliran, Uji model / prototipe, pengukur debit, pengukur kecepatan aliran (current meter), pengukur elevasi air manual, pengukur tinggi air otomatis (Divers), kolam sebagai reservoir. (Riffin \& Ahmad, 2015). Komponenkomponen yang membentuk aliran tertutup dibuat skema dalam Gambar 1.

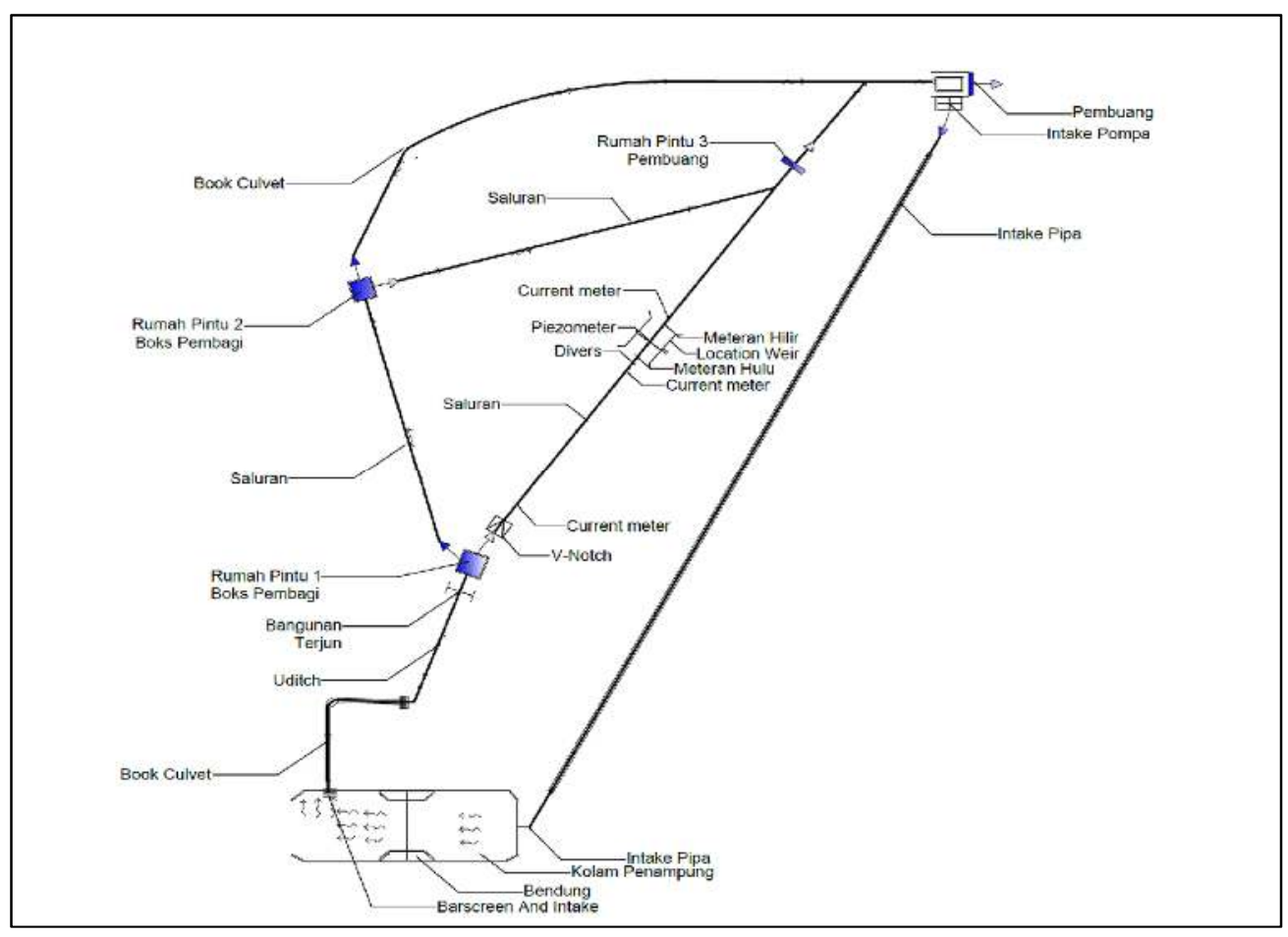

Gambar 1. Langkah Kerja Pengujian Model Fisik Laboratorium 
Siklus aliran eksperimen Labo Hidrolika FT Unissula, secara urut disampaikan dalam paragraph ini. Yang pertama intake air ke pompa diambil dari kolam tampungan air. Kedua pompa mengambil air dan mengirim ke tandon air laboratorium, tendon ini dilengkapi bendung pengatur dan penyaring kotoran (M.A.O.A Khalifa, I. Wahyudi, \& P. Thomas, 2000). Ketiga melalui saluran air dibawa menuju pintu kontrol berupa boxculvert, pintu air tersebut membagi aliran ke kiri dan lurus. Keempat aliran air lurus ke Vnotch atau pintu Thomson sebagai pengukur debit secara manual. Kelima alat Current meter mengukur kecepatan aliran air dan divers mengukur fluktuasi elevasi air. (De Paola \& Marini, 2011) Keenam aliran tersebut digunakan uji prototipe bendung porous dengan beberapa bentuk dan jenis materialnya. Aliran yang melalui bendung porous kemudian kembali ke kolam tambungam. Variasi uji meliputi bentuk dan jenis material model, kemudian variasi debit aliran dan beda tinggi yang diterapkan.

Untuk memudahkan pemahaman dari siklus aliran tertutup, disampaikan secara urut beberapa foto dari komponen aliran tersebut. Pada gambar 2 ditampilkan foro dari pompa yang menyedot air dari tampungan air alami yang letaknya di belakang Fakultas Teknik. Air yang dipompa tersebut dimasukkan dalam tandon laboratorium.

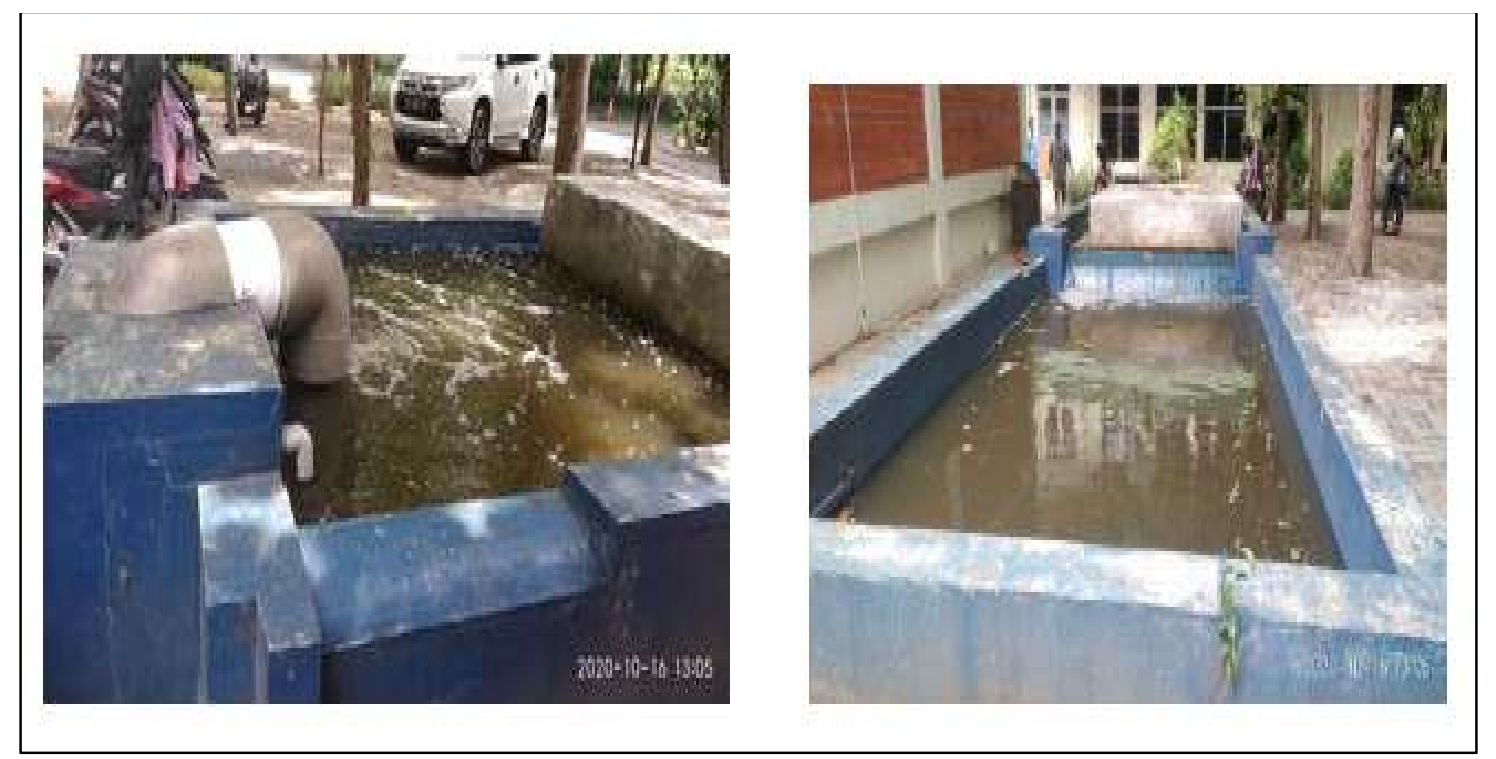

Gambar 2. Komponen pompa dan tandon air di laboratorium 
Pada Gambar 3 menampilkan foto pintu pembagi dan pengatur aliran air. Arah lurus saluran digunakan untuk uji model bendung porous yang akan disampaikan dalam paragraf berikutnya.

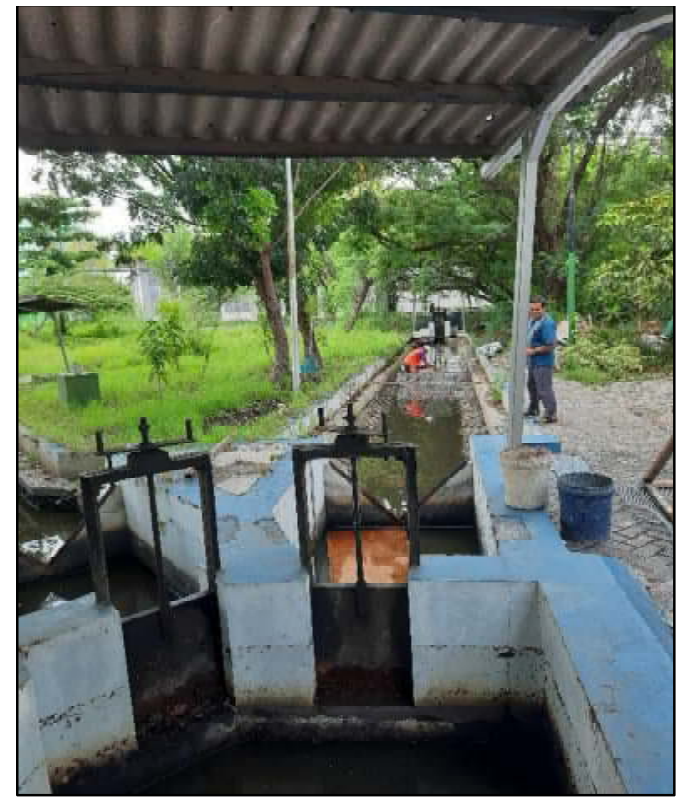

Gambar 3. Pintu air dan saluran pengatur aliran ke model Bendung

Aliran yang lurus menuju ke model uji hidrolika diukur debit dan fluktuasi elevasi air. Gambar 4 menampilkan pemasangan alat ukur kedua parameter tersebut.

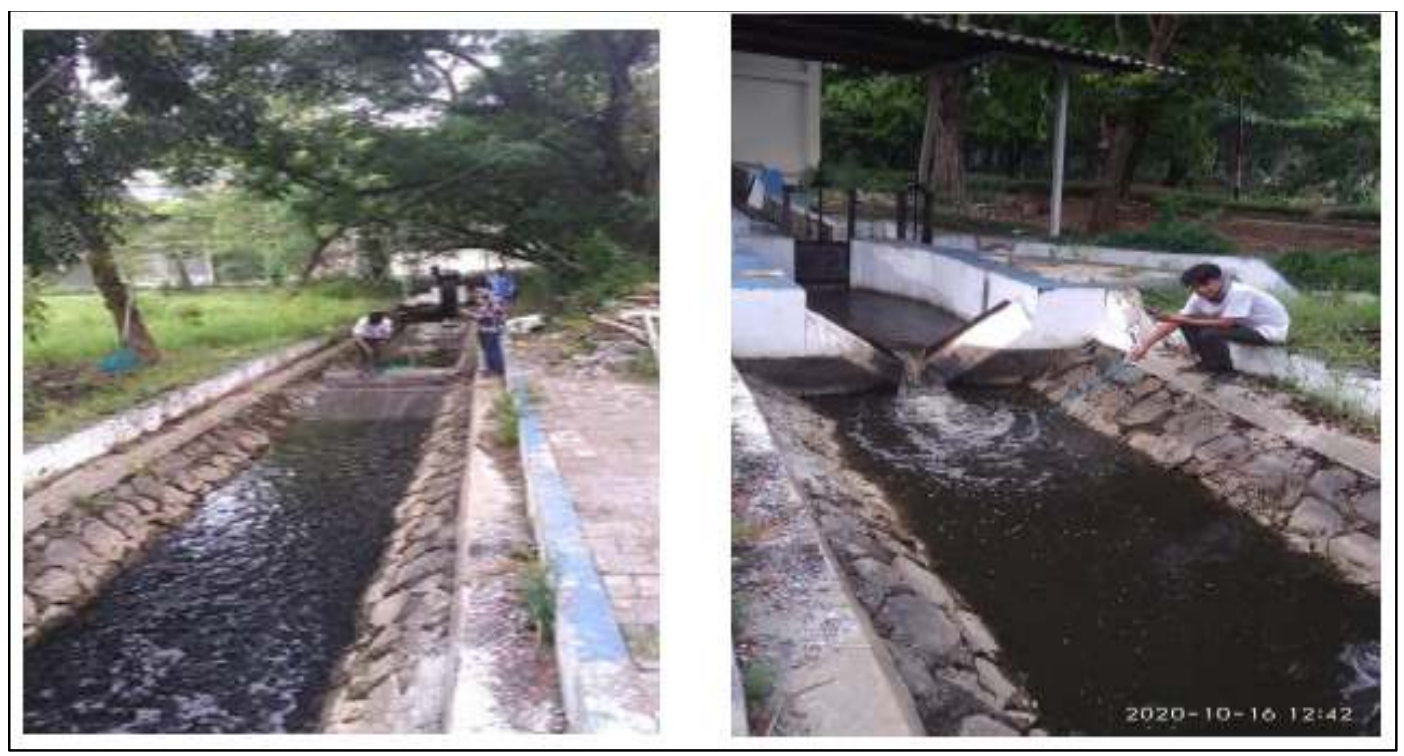

Gambar 4. Pengukuran Debit dan elevasi air 


\subsection{Inisiasi eksperimen Bendung Berpori untuk kawasan pertanian}

Pada umumnya konstruksi bendung memiliki sifat kedap air. Untuk beberapa keperluan, bendung juga dibuat yang bersifat berpori (Ky \& Chhun, 2018). Diantara fungsi bendung berpori adalah pengambilan bebas aliran yang beda tinggi tidak besar diperlukan, menyaring air dari upstream, modifikasi pemanfaatan saat musin penghujan dan kemarau (Boogaard and Lucke, 2019). Bendung tersebut akan digunakan sebagai teknologi tepat guna dalam mengatasi banjir rob pada daerah lokasi banjir yang air nya akan dimanfaatkan menjadi air baku (Andrea G. Capodag/io, Paolo Ghilardi, \& Joanna BoguniewiczZab/ocka, 2016). Penelitian ini bertujuan untuk mengamati elevasi air tiga model bendung bronjong. Pada pengujian prototipe di laboratorium Hidrolika Universitas Islam Sultan Agung Semarang.

Metode pengujian laboratorium dapat menggunakan model fisik dengan skala diperkecil atau skala sama (undistorted scale). Model fisik hidraulik sering disebut sebagai model skala adalah peniruan bangunan prototipe ke dalam suatu model miniature skala tertentu dengan memperhatikan prinsip kesebangunan dan hubungan antar skala parameter yang harus dipenuhi (Costa, Burlando, \& Priadi, 2016). Apabila hubungan antar skala dan kesebangunan telah dipenuhi, maka hasil eksperimen dengan kalkulasi implementasi lapangan dapat dianalisis (Sharp, 1981).

Skala model yang digunakan dalam pengujian ini didasarkan pada beberapa pertimbangan antara lain tujuan dari pengujian, ketelitian, fasilitas laboratorium dan biaya. (Mah, Putuhena, \& Rosli, 2011). Berdasar pengamatan lapangan di kawasan pertanian, model laboratorium ini memiliki lebih kurang skala $1 / 2$ (setengah) dari riel di lapangan. Pengujian model fisik bendung porus dilakukan di laboratorium hidrolika Fakultas Teknik Universitas Islam Sultan Agung Semarang. Desain model bendung porus dibagi dalam 3 bentuk/tipe. Tipe 1 menggunakan bendung bronjong dengan model kedua sisi berlapis 3, 2 dan 1 (miring). Tipe 2 menggunakan bendung bronjong dengan model bagian hulu mempunyai sisi tegak, sedangkan bagian hilir sisi miring (berlapis 2,5, 2 dan 1,5). Tipe 3 menggunakan bendung bronjong dengan model tegak satu lapis.Untuk awal uji model bendung berpori, dipresentasikan hanya model yang pertama yaitu model bronjong sisi miring. Berikut gambar konstruksi bendung berpori tersebut. 


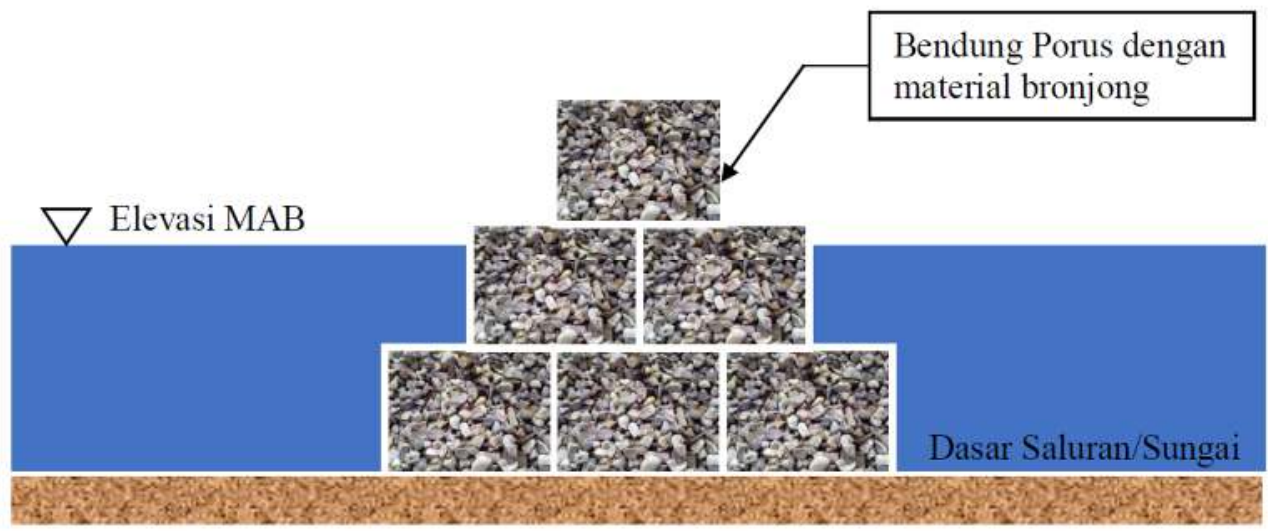

Gambar 5. Desain Potongan Model Bendung Porus Tipe 1

Material yang dipakai untuk model bendung porous adalah material agregat kasar beton dengan diameter antara 4-5 $\mathrm{cm}$. kemudian dibentuk dengan bronjong galvanis diameter lubang $1-2 \mathrm{~cm}$. Bendung tersebut memilikibentuk trapesium dengan dimensi sampel yaitu Panjang $=1,50 \mathrm{~m}$, Lebar $=2,30 \mathrm{~m}$, Tinggi $=0,65 \mathrm{~m}$. berdasarkan kondisi saluran yang dimilik labo dimensi saluran juga trapezium dengan dimensi $\mathrm{b}=2,30 \mathrm{~m}, \mathrm{~h}=$ $1,0 \mathrm{~m}$. Berikut ilustrasi dari konstruksi saluran dan uji sampel bendung berpori.

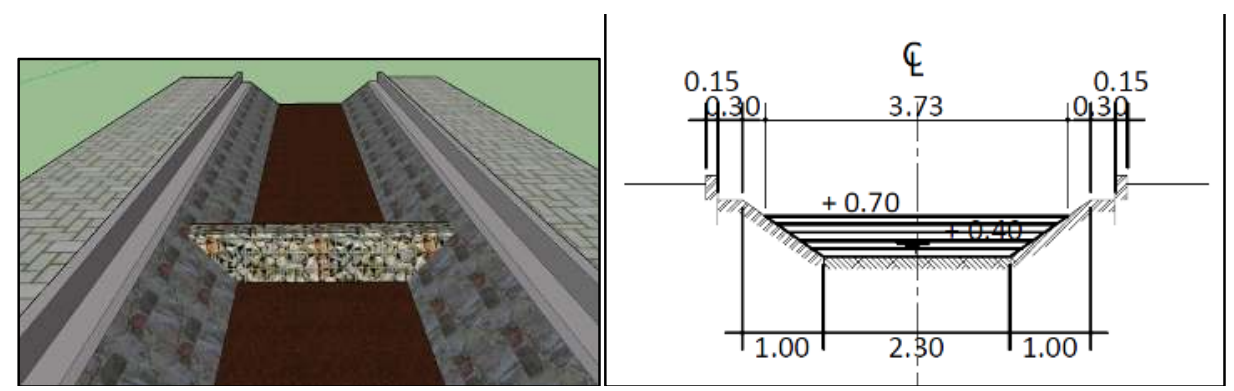

Gambar 6. Gambar Tampak Rencana eksperimen uji hidrolik

Dalam penelitian ini yang diamati dan diukur adalah debit dan kecepatan aliran, tinggi air di hulu dan hilir bendung dari beberepa tipe model bendung berpori. Hasil Uji model Desain didapat bendung beronjong tipe 1 elevasi MA hulu bendung $=+65 \mathrm{~cm}$, center bendung $=+44.5 \mathrm{~cm}$, hilir bendung $=+41 \mathrm{~cm}$. Hasil Uji model Desain didapat bendung bronjong tipe 2 elevasi MA hulu bendung $=+48.76 \mathrm{~cm}$, elevasi center bendung $=+45,5 \mathrm{~cm}$, hilir bendung $=+43 \mathrm{~cm}$. Hasil Uji model Desain didapat bendung bronjong tipe 3 elevasi MA hulu bendung $=59 \mathrm{~cm}$, elevasi center bendung $=49.5 \mathrm{~cm}$, hilir bendung $=40 \mathrm{~cm}$. pengukuran elevasi otomatis ini ditampilkan dalam grafik sebagai berikut. 


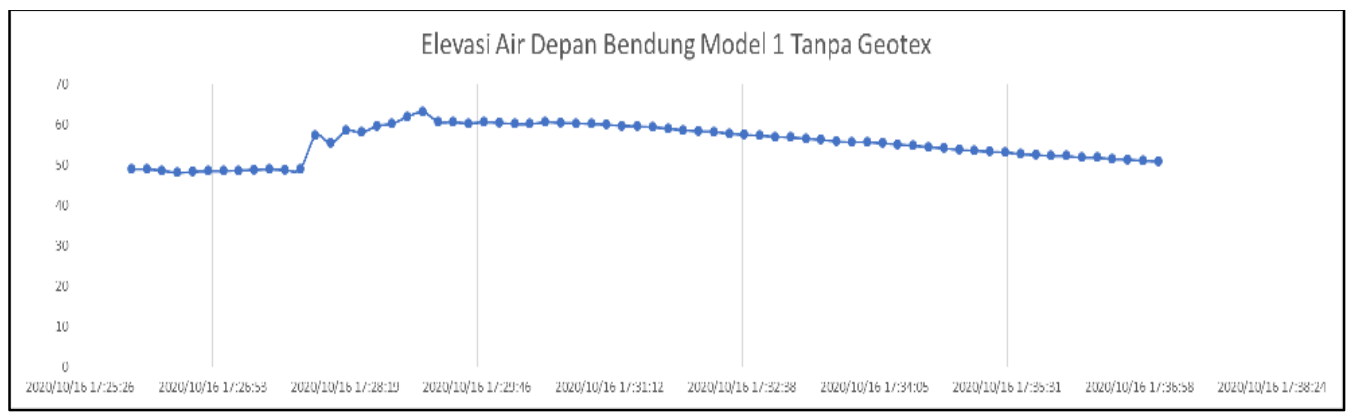

Gambar 7. Contoh Grafik hasil pengamatan elevasi air di hulu bendung

Untuk memperjelas lebih rinci hasil penelitian dipresentasikan elevasi, kecepatan dan temperature dalam fungsi waktu dalam Tabel 1.

Tabel 1. Contoh hasil pengamatan eksperimen laboratorium

\begin{tabular}{|c|c|c|c|c|c|c|c|c|c|c|}
\hline \multirow{2}{*}{ No } & \multirow{2}{*}{$\begin{array}{c}\text { Model } \\
\text { Bendung }\end{array}$} & \multicolumn{3}{|c|}{ Elevasi $(\mathrm{Cm})$} & \multicolumn{3}{|c|}{ Kecepatan (I/s) } & \multicolumn{3}{|c|}{ Temperatur (derajat) } \\
\hline & & Hulu & Center & Hilir & Hulu & Center & Hilir & Hulu & Center & Hilir \\
\hline 1 & \multirow{6}{*}{ Tyepe 1} & 45 & 40 & 38 & 1.6 & 0.75 & 0.6 & 36 & 36 & 36 \\
\hline 2 & & 58 & 43 & 40 & 1.6 & 0.75 & 0.6 & 36 & 36 & 36 \\
\hline 3 & & 59 & 49 & 41 & 1.6 & 0.75 & 0.6 & 36 & 36 & 36 \\
\hline 4 & & 59 & 49 & 39 & 1.6 & 0.75 & 0.6 & 36 & 36 & 36 \\
\hline 5 & & 59 & 49.5 & 40 & 1.6 & 0.75 & 0.6 & 36 & 36 & 36 \\
\hline 6 & & 60 & 50 & 40 & 1.6 & 0.75 & 0.6 & 36 & 36 & 36 \\
\hline
\end{tabular}

Hasil awal tersebut di atas akan dilanjutkan dengan beberapa simulasi bentuk bendung, beda tinggi air, kecepatan aliran, sehingga di dapat rumusan metode mendapatkan desain bendung berpori yang efisien. Bendung berpori ini akan diplikasikan di kawasan pertanian dimana pada saat musim penghujan dan kemarau berbeda kebutuhan airnya. Sehingga diperlukan penutup yang fleksibel bendung berpori ini.

\section{KESIMPULAN DAN SARAN}

Penelitian ini bertujuan untuk menambahkan komponen uji aliran tertutup dan uji coba aliran dengan sampel berupa bendung berpori. Hasil penelitian ini meliputi data invetori kondisi eksisting laboratorium, pembuatan denah eksisting, perencanaan sirkulasi aliran, alat ukur yang diperlukan, alokasi uji model bangunan, detail perencanaan laboratorium uji hidrolika. Penelitian ini diawali dengan uji aliran bendung berpori. Luaran Penelitian ini berupa perencanaan laboratorium untuk uji dan penelitian, perbaikan alur aliran dan uji awal eksperimen laboratorium untuk bendung berpori. 
Jurnal Planologi Vol. 18 No. 1, April 2021 Available: http://jurnal.unissula.ac.id/index.php/psa

\section{UCAPAN TERIMA KASIH}

Beberapa mahasiswa yang membantu, Bantuan pendanaan Penelitian internal melalui LPPM UNISSULA, yang juga terintegrasi dengan Hibah Penelitian dari DRPM Kemenristek-BRIN RI.

\section{DAFTAR PUSTAKA}

Andrea G. Capodag/io, Paolo Ghilardi, \& Joanna Boguniewicz-Zab/ocka. (2016). New paradigms in urban water management for conservation and sustainability. Water Practice and Technology, 11(1), 176-186. https://doi.org/10.2166/wpt.2016.022

Boogaard, F., Heikoop, R., Boer, E., \& Palsma, M. (2017). Effective International Knowledge Exchange to Rehabilitate Rivers in Urban Delta's with RDM approach. In MATEC Web of Conferences (p. 13).

Boogaard, Floris and Lucke, T. (2019). Long-Term Infiltration Performance Evaluation of Dutch Permeable Pavements Using the Full-Scale Infiltration Method. Journal of Water, 11, 1-13. https://doi.org/10.3390/w11020320

Costa, D., Burlando, P., \& Priadi, C. (2016). The importance of integrated solutions to flooding and water quality problems in the tropical megacity of Jakarta. Sustainable Cities and Society, 20. https://doi.org/10.1016/j.scs.2015.09.009

De Paola, F., \& Marini, G. (2011). Experimental Research on Floodplain Storage Inundation: Preliminary Results. Energy and Environment Research, 1(1), 53-60. https://doi.org/10.5539/eer.v1n1p53

Hiwasaki, L., Luna, E., Syamsidik, \& Shaw, R. (2014). Process for integrating local and indigenous knowledge with science for hydro-meteorological disaster risk reduction and climate change adaptation in coastal and small island communities. International Journal of Disaster Risk Reduction, 10. https://doi.org/10.1016/j.ijdrr.2014.07.007

Ky, S., Martinez, J., \& Chhun, S. (2018). Mechanical Stability of River Banks Submitted to Fluctuations of the Water Level. In Advances in Multi-Physics and Multi-Scale Couplings in Geo-Environmental Mechanics. https://doi.org/https://doi.org/10.1016/B978-1-78548-278-6.50010-4

M.A.O.A Khalifa, I. Wahyudi, \& P. Thomas. (2000). A New Device for Measuring Permeability Under High Gradients and Sinusodal Gradients. Geotechnical Testing Journal, 23(4), 404-412. https://doi.org/10.1520/GTJ11061J

Mah, D. Y. S., Putuhena, F. J., \& bt Rosli, N. A. (2011). Modelling of river flushing and 
water quality in a tributary constrained by barrages. Irrigation and Drainage Systems. https://doi.org/10.1007/s10795-011-9122-1

Niken RTH, R., Imam Wahyudi, S., \& Poedjiastoeti, H. (2019). Ecodrainage Model to Handle the Inundations in the City Center of Demak. Journal of Advanced Civil and Environmental Engineering, 2(2), 85-96. https://doi.org/10.30659/jacee.2.2.85-96

Riffin, J., \& Ahmad, H. (2015). Experimental Study on Local Scour Before and After the Channel Bend. In InCIEC2015 (pp. 43-50). Selangor: Springer. https://doi.org/110.1007/978-981-0

Tsuchiya, K., Hara, Y., \& Thaitakoo, D. (2015). Linking food and land systems for sustainable peri-urban agriculture in Bangkok Metropolitan Region. Landscape and Urban Planning, 143. https://doi.org/10.1016/j.landurbplan.2015.07.008

Wahyudi, S. I., Adi, H. P., \& Lekkerkerk, J. (2019). Handling Solution Tidal Flood in Kaligawe Area by Polder System Drainage. International Journal of Innovative Technology and Exploring Engineering, 9(2), 1104-1109. https://doi.org/10.35940/ijitee.13450.129219 